\title{
Applications of M-GARCH Model for the Selection of Securities of Banks' Investment Portfolio
}

\author{
Eleftherios I. Thalassinos ${ }^{1}$, Bozhana Venediktova ${ }^{2}$ \& Vicky Zampeta ${ }^{3}$ \\ ${ }^{1}$ University of Piraeus, Department of Maritime Studies, Piraeus 18533, Greece. \\ ${ }^{2}$ University of National and World Economy, Department of Finance, Sofia, Bulgaria. \\ ${ }^{3}$ University of Piraeus, Department of Maritime Studies, Piraeus 18533, Greece. \\ Correspondence: Eleftherios I. Thalassinos, University of Piraeus, Department of Maritime Studies, Piraeus 18533, \\ Greece.
}

Received: December 29, 2014

Accepted: January 16, 2015

Available online: March 11, 2015

doi:10.11114/aef.v2i2.711

URL: http://dx.doi.org/10.11114/aef.v2i2.711

\begin{abstract}
The main aim of this article is to investigate the accuracy of the Multivariate Generalized Autoregressive Conditional Heteroskedasticity Model (M-GARCH) for the selection of the best investment portfolio. There is extended literature on M-GARCH in this field with a great number of studies using different sets of variables among them the returns of assets, the volatility of the assets in the investment portfolio, the maturity date of the asset etc. The origin of M-GARCH is associated with the elements of the Dynamic Conditional Correlations Model (DDCM) as proposed by Engle. An earlier version of DDCM with time variations in the correlation matrix has been developed by Bollerslev. DCCM offers flexibility by incorporating different levels of volatilities able to structure portfolios with a great number of assets. M-GARCH models take into account separate univariate GARCH models, associate with each asset in the portfolio, in order to form a complete M-GARCH model. The present article uses a multiple dimension classic M-GARCH volatility model on a data set consisting from three time series. The daily ASE index on stock returns (Athens), the DAX index (Germany) and the CAC index (France). For each national index, the continuously compounded return was estimated as $\mathrm{rt}=100[\log (\mathrm{pt})-\log (\mathrm{pt}-1)]$, where $\mathrm{pt}$ is the price on day $\mathrm{t}$.
\end{abstract}

Keywords: commercial banks, m-garch models, portfolio selection, forecasting

JEL Classification: F23, G21

\section{Introduction}

Stock returns are closely related to risk associated with each asset in a selected investment portfolio. Risk management, especially in unstable conditions, has been characterized as the core issue in market valuations and returns with a great number of studies both from researchers and practitioners (Thalassinos et al., 2010). In many cases the complexity of the set of assets on one hand and the different levels of uncertainty on the other have leaded to new methods and tools in risk management as has been pointed out by Thalassinos and Pociovalisteanu (2007) and Thalassinos et al. (2013). Risk management is associated with the acceptance or not of the level of uncertainty in the selection of any investment portfolio. It is a process going through the identification stage, the stage of risk analysis and the final decision stage where the analyst has to decide which portfolio is the most desirable by the investor. Risk management is an effective tool to be used for greater rewards and not only to control losses. Stop losses decisions are considered of equal importance as decisions maximizing gains. It is also an analytic procedure with multidisciplinary perspectives, methods and processes for the optimization of risk against gain, a field that together with its financial aspect has experienced a fast and advanced growth at an incredible speed (Thalassinos et al., 2009; Thalassinos et al., 2010).

Ustun (2012) has described the traditional financial risk management approach on the mean-variance framework of portfolio theory through a selection and diversification process. Financial econometrics have been used as the most appropriate method to understand and predict the temporal dependence in the second-order moments of asset returns. Recent studies have shown that financial volatilities move together across assets and markets (Thalassinos et al., 2006; Thalassinos et al., 2012). By accepting this characteristic through a multivariate process such as the M-GARCH model leads to more relevant empirical models, more dynamic and more accurate than working with a set of different 
univariate models. This is a very important result from both, a financial and a computational point of view, because it creates the appropriate procedure for a more effective prediction tool for various perspectives, such as asset pricing, portfolio selection, option pricing, hedging and risk management.

Bauwens (2006) has applied M-GARCH models to analyze the relations between the volatilities and co-volatilities of several markets. In other studies M-GARCH models have been used for the computation of time-varying hedge ratios. Ordinary Least Squared (OLS) methodology has been also used for the estimation of hedge ratios. The coefficient of the slope of the regression equation is considered as the spot return on the futures return, because this is equivalent by estimating the ratio of the covariance between spot and futures over the variance of the futures.

\section{M-GARCH Model}

The present article considers an M-GARCH model to analyze the relationship between returns of governments bonds and volatilities of stock index prices in a dynamic way (Tastan, 2006).

The level of volatility of a certain series (for example asset returns $r_{t}$ ) is generally measured by its conditional variance and is denoted by equation (1):

$$
h_{1} t^{\dagger} 2=\operatorname{Var}\left(r_{1} t \mid \mathcal{F}_{1}(t-1) \downarrow\right)
$$

The level of volatility of an asset depends on a set of factors. Such factors are the degree of over-reaction or under-reaction to news, some incomplete and non-updated information, parameter variations, possible changes in global financial institutions (e.g. International Monetary Fund, World Bank, European Monetary Union) and abrupt switches in policy regimes (Thalassinos, Maditinos and Paschalidis, 2012). The level of volatility in asset returns can be estimated with two different ways. Either by using the option prices or time series data as they are reported in real transactions. Most of the econometric methods which have been used to evaluate volatility are based on daily observations. Forecasts of the level of volatility are used in risk management procedures, in option pricing and in asset portfolio decisions. In most cases M-GARCH volatility models have been extensively used. Engle (1982) has proposed a GARCH model to capture volatility variation for the first time.

\subsection{DCC and t-DCC Multivariate Volatility Models}

The Dynamic Conditional Correlations (DCC) model is an estimation procedure which is reasonable flexible in modeling individual levels of volatilities for sets of assets that can be applied to portfolio with a large number of assets. To evaluate the fat-tailed nature of the distribution of asset returns, it is more appropriate if the DCC model is combined with a multivariate t-distribution, particularly for risk analysis where the tail properties of return distributions are of primary concern.

Let $r_{t}$ be a $\mathrm{m}^{\times} 1$ vector of asset returns at close day $\mathrm{t}$ assumed to have mean $\mu_{t-1}$ and the non-singular variance-covariance matrix $\sum_{t-1}$ which decomposes as follows (Bollerslev, 1990; Engle, 2003):

$$
\sum_{t-1}=D_{t-1} R_{t-1} D_{t-1}
$$

Where,

$$
D_{t-1}=\left[\begin{array}{cccc}
\sigma_{1, t-1} & 0 \cdots & & 0 \\
0 & \sigma_{2, t-1} & \ddots & \vdots \\
0 & 0 & \cdots & \sigma_{m, t-1}
\end{array}\right]
$$




$$
R_{t-1}=\left[\begin{array}{cccccc}
1 & \rho_{12, t-1} & \rho_{13, t-1} & \ldots & \rho_{1 m, t-1} \\
\rho_{21, t-1} & 1 & \rho_{23, t-1} & \ldots & \rho_{2 m, t-1} \\
& \vdots & \ddots & \vdots & & \\
\vdots & & & \rho_{m-1, t-1} & \\
\rho_{m 1, t-1} & \ldots & \ldots & \rho_{m, m-1, t-1} & 1
\end{array}\right]
$$

In matrices (3) and (4) $\sigma_{i, t-1}^{2}$ is the conditional volatility defined by

$$
\sigma_{1}(i, t-1)^{\mathrm{T}} 2=V\left(r_{\downarrow} i t \mid \Omega_{\rrbracket}(t-1) \downarrow\right)
$$

and $\rho_{i j, t-1}$ are the conditional pair-wise return correlations defined by

$$
\rho_{i j, t-1}=\frac{\operatorname{cov}\left(r_{i t} T_{j t} \mid \Omega_{t-1}\right)}{\sigma_{i, t-1} \sigma_{j, t-1}}
$$

Where, $\Omega_{t-1}$ is the information set available at close of day t-1.

Clearly, $\rho_{i j, t-1}=1$, for $\mathrm{i}=\mathrm{j}$.

The estimation is by maximum likelihood, well known in the literature as DCC model:

$$
\begin{gathered}
\sigma_{i, t-1}^{2}=\bar{\sigma}_{i}^{z}(1- \\
\left.\lambda_{\downarrow} 1 i-\lambda_{\downarrow} 2 i\right)+\lambda_{\downarrow} 1 i \sigma_{\downarrow}(i, t-2)^{\uparrow} 2+\lambda_{\downarrow} 2 i r_{\downarrow}(i, t-1)^{\mathrm{\tau} 2}, i=1, \ldots, m \\
\tilde{\rho}_{i j, t-1}(\delta)=\frac{q_{i j, t-1}}{\sqrt{q_{i i_{1}, t-1} q_{j j, t-1}}} \quad, \mathrm{i}^{\neq} j=1, \ldots, m
\end{gathered}
$$

In equation (7) $\bar{\sigma}_{i}^{\boldsymbol{z}}$ is the unconditional variance of $\mathrm{i}^{\text {th }}$ asset return, and $\lambda_{1 i}, \lambda_{\mathbf{2} i}$ for $i=1_{y \ldots \ldots}, m$ are the unknown parameters.

\subsection{Forecasting Volatilities and Conditional Correlations}

Having obtained the recursive ML estimates, $\tilde{\theta}_{t}$, given by $\tilde{\theta}_{t}=\arg \max _{\theta}\left\{l_{t}(\theta)\right\}$, the following one step ahead forecast can be obtained. For volatilities we have:

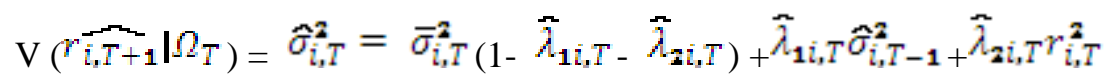

Where $\bar{\sigma}_{i, T}^{\boldsymbol{z}}$ is the estimate of the unconditional mean of ${ }^{2} \boldsymbol{z}, T$ computes as:

$$
\bar{\sigma}_{i, T}^{2}=T^{-1} \sum_{i=1}^{T} r_{i, T}^{2}
$$


$\hat{\lambda}_{1 i, T}$ and $\hat{\lambda}_{2 i, T}$ are the ML estimates of the $\lambda_{1 i, T}$ and $\lambda_{2 i, T}$ computed using the observations over the estimation sample $S_{\text {est }}=\left(\Gamma_{1} t, t=s_{y} s+\mathbf{1}_{y} \ldots \ldots, T\right)$ and $\hat{\sigma}_{i, T-1}^{z}$ is the ML estimate of $\sigma_{i, T-1}^{z}$ based on the estimates $\bar{\sigma}_{i, T}^{z}, \bar{\lambda}_{1 i, T-1}, \quad \tilde{\lambda}_{\mathbf{z} i, T-1}$.

Similarly, the one-step ahead forecast of $\rho_{i j, T}$ (using either exponentially weighted returns or devolatilized returns) is given by:

$$
\rho_{1}(i j, T)(\varphi)=\sqrt{\frac{\hat{q}_{i j, T}}{\hat{q}_{i i, T} \hat{q}_{j j, T}}}
$$

Where $\hat{q}_{i j, T}=\hat{p}_{i j, T}\left(1-\hat{\varphi}_{1, T}-\hat{\varphi}_{2, T}\right)+\hat{\varphi}_{1, T} \hat{q}_{i j, T}+\hat{\varphi}_{2, T} \hat{F}_{i, T} \hat{F}_{j, T}$

As before $\hat{\varphi}_{1, T}$ and $\hat{\varphi}_{2, T}$ are ML estimates of $\varphi_{1, T}$ and $\varphi_{2, T}$ computing using the estimation sample, $\hat{q}_{i j, T}$ is the ML estimate $q_{i j, T-1}$, based on the estimates $\bar{\rho}_{i j, T-1}, \hat{\varphi}_{1, T-1}$ and $\hat{\varphi}_{2, T-1}$.

\section{Empirical Studies in Financial Instruments}

In this section we have chosen three 10-years government bonds issued in Greece (ASE), Germany (DAX) and France (CAC40), as well as equity indices of these three countries to demonstrate the application of M-GARCH model. The data series used are from January 07, 2008 to May 30, 2014. (Sources: Financial Times ${ }^{1}$ website, Yahoo ${ }^{2}$ Finance). We have used the daily expected returns as the dependent variable in all selected models. The data series gives 1602 observations for each instrument. Based on the estimated model we have prepared forecasts for the period December 2012 to May 2014 excluding no working days.

The empirical evidence on the relationship between returns of government bonds and volatilities of stock indexes is mixed. In some cases there is positive correlation and in some others we can see significant time-varying correlation. We consider that large capital flows from global financial institutions (for example IMF) may lead to significant changes and volatilities. However, compared with other countries, e.g. Germany and France, we observe the opposite due to the fact that there is not significant foreign intervention (Tastan, 2006).

\subsection{Summary Statistics}

By using regression analysis it is possible to estimate the effects of information received on volatilities and covariance. The regression coefficients of daily expected returns for the three countries under consideration are presented in the Appendix.

In order to describe the proposed model we assume that the $\mathrm{m}^{\times} 1$ vector of returns $r_{t}$ follows a multivariate Student's t-distribution, though the same line of reasoning applies in the case of the Gaussian returns. By considering it as a portfolio based on $m$ assets with returns $r_{t}$, using a $\mathrm{m}^{\times} 1$ of predetermined weights, $w_{t-1}$ the return on this portfolio is given by equation (13) as follows:

$$
\rho_{t}=w_{t-1}^{x} r_{t}
$$

We now suppose that we are interested in computing the capital Value at Risk $(\mathrm{VaR})$ of this portfolio, expected at the close of business on day $\mathrm{t}-1$ with probability $1-\alpha$, which we denote by VaR ( $w_{t-1}, \alpha$ ). For this purpose we require that

\footnotetext{
${ }^{1}$ http://markets.ft.com/research/Markets/Bonds

${ }^{2}$ http://finance.yahoo.com/
} 


$$
P_{r}\left[w^{s}{ }_{t-1} r_{t}<-\operatorname{VaR}\left(w_{t-1}, \alpha\right) \mid \Omega_{t-1}\right] \leq \alpha
$$

Under our assumptions, conditional on $\Omega_{t-1}, w^{t} t_{t-1} r_{t}$ has a student t-distribution with mean $w^{R}{ }_{t-1} \mu_{t-1}$ variance $w_{t-1}^{n} \sum_{t-1}$ and degrees of freedom $v$

Therefore,

$$
z_{t}=\sqrt{\frac{v}{v-2}}\left(\frac{w_{t-1}^{s} f_{t}-w_{t-1}^{s} \mu_{t-1}}{\sqrt{w_{t-1}^{n} \sum_{t-1} \equiv w_{t-1}}}\right)
$$

Conditional on $\Omega_{t-1}$, will also come out on a student's t-distribution with $v$ degrees of freedom. It is easy to verified that $\mathrm{E}\left(z_{\downarrow} t \mid \Omega_{\Downarrow}(t-1)\right)=0-$ and $\mathrm{V}\left(z_{t} \mid \Omega_{t-1}\right)=v /(v-2)$. Denoting the cumulative distribution function of a student's t-distribution with $v$ degrees of freedom by $F_{v}(\mathrm{z}), \mathrm{VaR}\left(w_{t-1}, \alpha\right)$ will be able to solve the function in equation (16) below as follows:

$$
F_{v}\left(\frac{-\operatorname{VaR}\left(w_{t-1}, \alpha\right)-w^{x}{ }_{t-1} \mu_{t-1_{v}}}{\sqrt{\frac{v}{v-2}\left(w_{t-1}^{n} \sum_{t-1} m w_{t-1}\right)}}\right) \leq \alpha
$$

But since $F_{v}(\mathrm{z})$ is a continuous and monotonic function of $\mathrm{z}$, we have equation (17) below as:

$$
\frac{-\operatorname{VaR}\left(w_{t-1}, \alpha\right)-w^{x}{ }_{t-1} \mu_{t-1},}{\sqrt{\frac{v}{v-2}\left(w^{x}{ }_{t-1} \sum_{t-1}{ }^{D} w_{t-1}\right)}}=F_{v}^{z}(\alpha)=-c_{\alpha}
$$

where $c_{\alpha}$ is the $\alpha$ per cent critical value of a student's t-distribution with $v$ degrees of freedom.

Therefore the Value at Risk function is now presented as in equation (18) below as:

$$
\begin{gathered}
\operatorname{VaR}\left(w_{t-1}, \alpha\right)=\sqrt{\left(w_{t-1}^{n} \sum_{t-1} w_{t-1}\right)}-w_{t-1}^{s} \mu_{t-1} \\
\bar{c}_{\alpha}=c_{\alpha} \sqrt{\frac{v}{v-2}}
\end{gathered}
$$

In Figure 1 the plots of the Value at Risk of the portfolio for $\alpha=0.01$, over the period from December 2012 to May 2014 is presented. It is clear from the Figure that VaR values were at the range of -135 to -50 in the whole study period. 


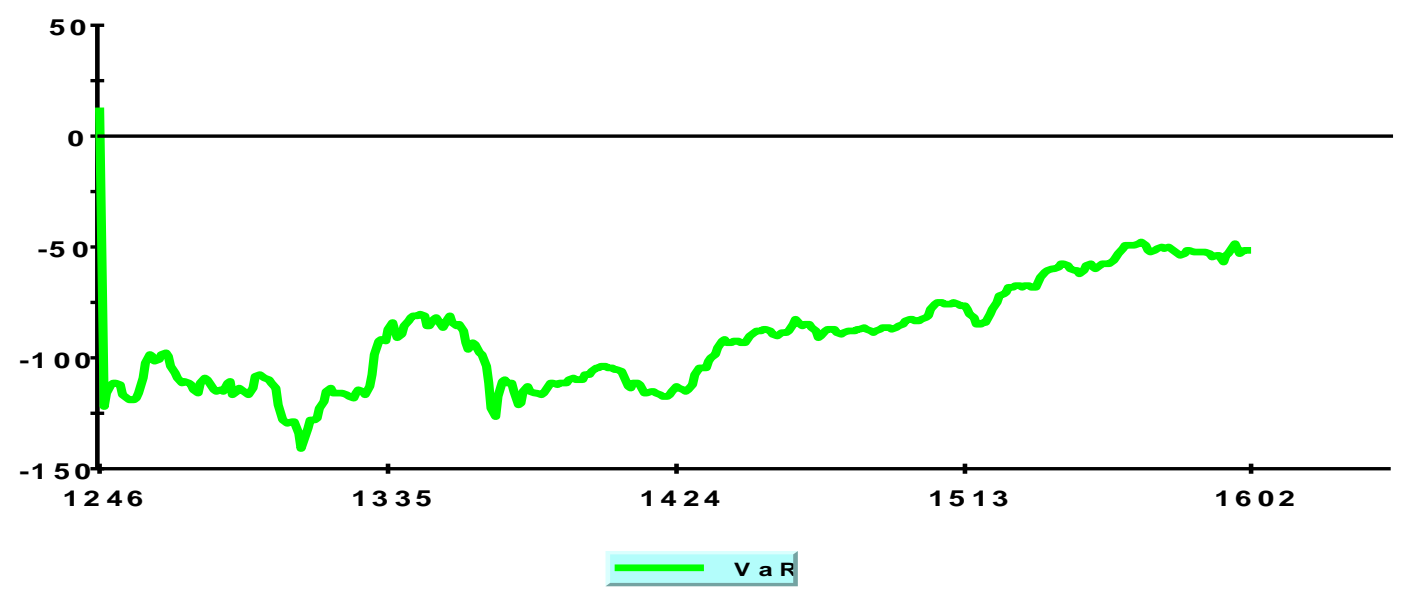

Figure 1. Value at Risk (December 2012-May 2014)

In Table 1 we present maximum likelihood estimates of $\lambda_{i 1}$ and $\lambda_{i z}$ for the three bonds futures returns and $\delta_{1}$, $\delta_{\mathbf{z}}$. It is obvious that asset specific estimates of the volatility decay parameters are all highly significant, with the estimates of $\lambda_{i 1} \quad i=1,2,3 \ldots 6$ to be very close to unity. The lower panel of the same Table 1 reports the estimated unconditional volatilities and correlations of the vector of assets. It is important to notice the high correlation between GM4 and FR4 (.33094) and between FR4 and GR2 (.0112).

Table 1. ML Estimates of the t-DCC Model on Futures Daily Returns

\begin{tabular}{|c|c|c|c|c|c|c|c|c|c|}
\hline & \multicolumn{3}{|c|}{ FR4 } & \multicolumn{3}{|c|}{ GM4 } & \multicolumn{3}{|c|}{ GR2 } \\
\hline & Estimate & SE & T-ratio & Estimate & SE & T-ratio & Estimate & SE & T-ratio \\
\hline$\Lambda 1$ & .403 & .0657 & $6.1346[.000]$ & .581 & .0721 & $8.06[.000]$ & .533 & .034 & $15.603[.000]$ \\
\hline \multirow[t]{2}{*}{$\Lambda 2$} & .485 & .0487 & $9.99[.000]$ & .28 & .04 & $6.978[000]$ & .385 & .027 & 14.191[.000] \\
\hline & \multicolumn{3}{|c|}{ Estimate } & \multicolumn{3}{|c|}{ SE } & \multicolumn{3}{|c|}{ T-ratio } \\
\hline$\Delta 1$ & \multicolumn{3}{|c|}{.981} & \multicolumn{3}{|c|}{.00442} & \multicolumn{3}{|c|}{$221.5972[.000]$} \\
\hline$\Delta 2$ & \multicolumn{3}{|c|}{.0172} & \multicolumn{3}{|c|}{.0034} & \multicolumn{3}{|c|}{$4.9838[.000]$} \\
\hline$v(d f)$ & \multicolumn{3}{|c|}{4.496} & \multicolumn{3}{|c|}{.245} & \multicolumn{3}{|c|}{$18.3366[.000]$} \\
\hline \multirow[t]{3}{*}{ MLL } & \multicolumn{9}{|l|}{3418.6} \\
\hline & \multicolumn{9}{|c|}{ Unconditional correlations } \\
\hline & \multicolumn{3}{|c|}{ FR4 } & \multicolumn{3}{|c|}{ GM4 } & \multicolumn{3}{|c|}{ AES2 } \\
\hline FR4 & \multicolumn{3}{|c|}{.0973} & \multicolumn{3}{|c|}{.33094} & \multicolumn{3}{|c|}{.0112} \\
\hline GM4 & \multicolumn{3}{|c|}{.33094} & \multicolumn{3}{|c|}{.080} & \multicolumn{3}{|c|}{-.0746} \\
\hline GR2 & \multicolumn{3}{|c|}{.0112} & \multicolumn{3}{|c|}{-.0746} & \multicolumn{3}{|c|}{.9693} \\
\hline
\end{tabular}

Notes: Based on 1221 observations from 25 to 1245.The underlying multivariate GARCH model is: CAC CAC(-1) CAC(-2) CAC(-3); DAX DAX(-1) DAX(-2) DAX(-3); GR ASE(-1) ASE(-2) ASE(-3); df is the degree of freedom;

The maximum log-likelihood value-MLL (3418.6) is significantly higher than the obtained value under normal 
assumption. The estimated degrees of freedom for the t-distribution are well below 30 suggesting that the $t$-distribution is more appropriate in capturing the fat tail nature of the distribution of asset returns.

\subsection{Plotting the Conditional Volatilities and Correlations}

Figure 2 presents the plot diagram of the conditional volatilities of bonds over the period January 2008 to May 2014.There are significant picks, far above the value 0.4 during the period especially in the case of Germany (GM4).

\section{Plot of conditional volatilities and correlations}

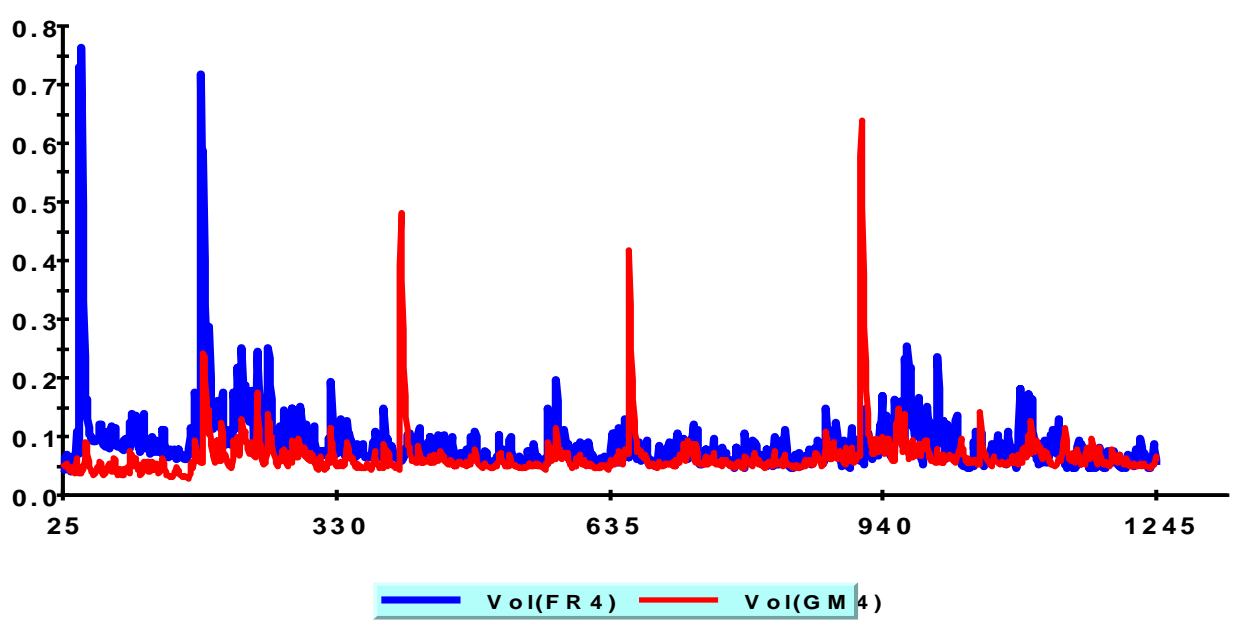

Plot of conditional volatilities and correlations

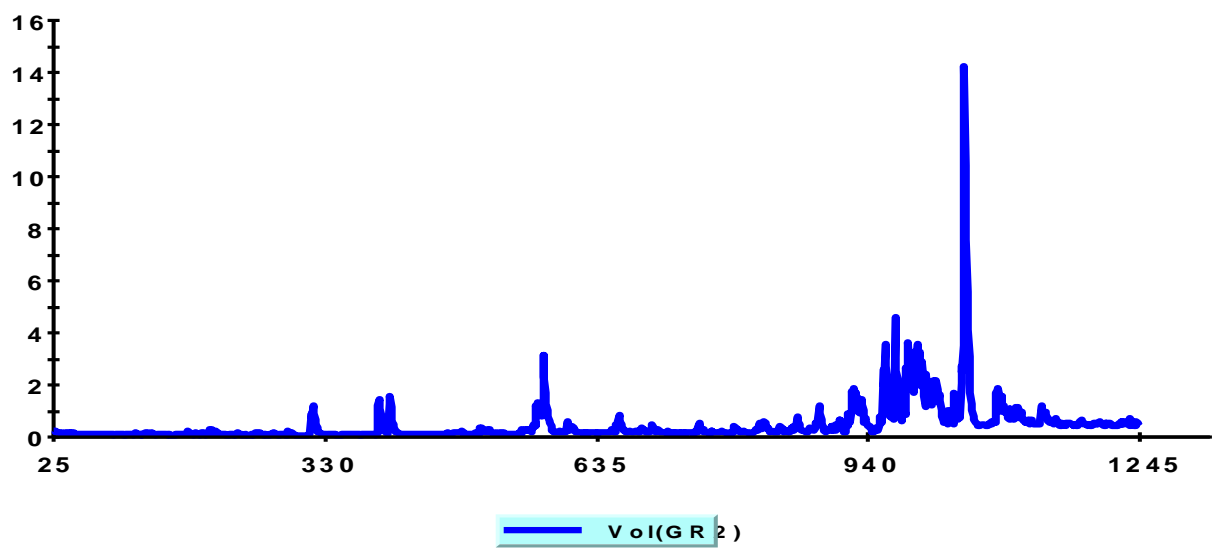

Figure 2. Conditional Volatilities of Bonds over the period January 07, 2008 to May 30, 2014

\subsection{Testing for Linear Restrictions}

In the previous sections we considered the estimated t-DCC model of stock indexes. Now we shall focus on the problem of testing the hypothesis that one of the assets returns has non-mean reverting volatility. That is let $\lambda_{i \mathbf{1}}$ and $\lambda_{i \boldsymbol{z}}$ is the parameters of the conditional volatility equation of $\mathrm{i}^{\text {th }}$ asset, and thus we should test the hypothesis:

$$
\mathrm{H}_{0}: \lambda_{i 1}+\lambda_{i 2}=1
$$

Under $\mathrm{H}_{0}$, the process is non-mean reverting and unconditional variance of this asset does not exist.

\subsection{Testing of the Validity of the t-DCC Model}

The estimates of t-DCC model are presented in Table 2. Each asset has equal weight in the portfolio. The results of LM test are presented in Table 3. Under the null hypothesis of correct specification of the t-DCC model, the probability of transform estimates are serially uncorrelated and uniformly distributed over the range $(0,1)$.The LM test equals to .1481E-4 with p-value of 0.000 , is statistically significant, thus not supporting the validity of t-DCC model. 
Table 2. Test of Serial Correlation (OLS case)-Validity of t-DCC Model (1246-1602 Observations)

\begin{tabular}{cccc}
\hline Regressor & Coefficient & SE & T-ratio \\
\hline OLS RES(-1) & $-.8899 \mathrm{E}-5$ & .053917 & $-.1651 \mathrm{E}-3[1.00]$ \\
OLS RES(-2) & $-.1583 \mathrm{E}-4$ & .053917 & $-.2935 \mathrm{E}-3[1.00]$ \\
OLS RES(-3) & $-.2415 \mathrm{E}-4$ & .053917 & $-.4478 \mathrm{E}-3[1.00]$ \\
OLS RES(-4) & $-.3248 \mathrm{E}-4$ & .053917 & $-.6023 \mathrm{E}-3[1.00]$ \\
OLS RES(-5) & $-.4022 \mathrm{E}-4$ & .053917 & $-.7459 \mathrm{E}-3[1.00]$ \\
OLS RES(-6) & $-.4687 \mathrm{E}-4$ & .053918 & $-.8693 \mathrm{E}-3[1.00]$ \\
OLS RES(-7) & $-.5580 \mathrm{E}-4$ & .053918 & $-.0010348[1.00]$ \\
OLS RES(-8) & $-.6409 \mathrm{E}-4$ & .053918 & $-.0011886[1.00]$ \\
OLS RES(-9) & $-.7218 \mathrm{E}-4$ & .053918 & $-.001484 .999]$ \\
OLS RES(-10) & $-.8003 \mathrm{E}-4$ & .053919 & $-.0016332[.999]$ \\
OLS RES(-11) & $-.8806 \mathrm{E}-4$ & .053919 & $-.0017729[.999]$ \\
OLS RES(-12) & $-.9559 \mathrm{E}-4$ & .053919 & $\mathrm{CHSQ}(12)=.1481 \mathrm{E}-4[.000]$ \\
LM-test & & & $\mathrm{F}(12,344)=.1189 \mathrm{E}-5[1.00]$ \\
F-version & & & \\
\hline
\end{tabular}

357 observations

Table 3. Mean VaR and the Associated Test Statistics

\begin{tabular}{lll}
\hline Mean HiT rate(pihat statistic & .0028011 & With expected of .9900 \\
\hline Standard normal test statistic & $-187.4654[.000]$ & \\
\hline
\end{tabular}

When we use the test of Kolmogorov-Smirnov, we have the results as shown in Figure 3. The figure compares the empirical cumulative distribution function of the probability integral transform variable with that of uniform schematic. The Kolmogorov-Smirnov test (0.988) is bigger than 5 per cent (critical value 0.0719) and hence, it rejects the null hypothesis of the probability that integral transforms are uniformly distributed. Histograms of the probability of integral transform variable is shown in Figure 4.

We use 0.01 as a tolerance probability of the VaR. The plot of the portfolio for the forecasting period from December 2012 to May 2014 is shown in Figure 5. The mean hit rate $\hat{\pi}_{\mathrm{N}}$ (equal to 0.0028) level, and $Z_{\pi}$ $(-187.465)$ under the tolerance 0.01 as shown in Table 2. Notice that $\hat{\pi}_{\mathrm{N}}$ is not close to expected value 0.990 , and that the test $Z_{\pi}$ is significant, both not supporting the validity of t-DCC model.

Kolmogorov-Smirnov Goodness-of-Fit Test $=.98720$ $5 \%$ Critical value $=.071979$

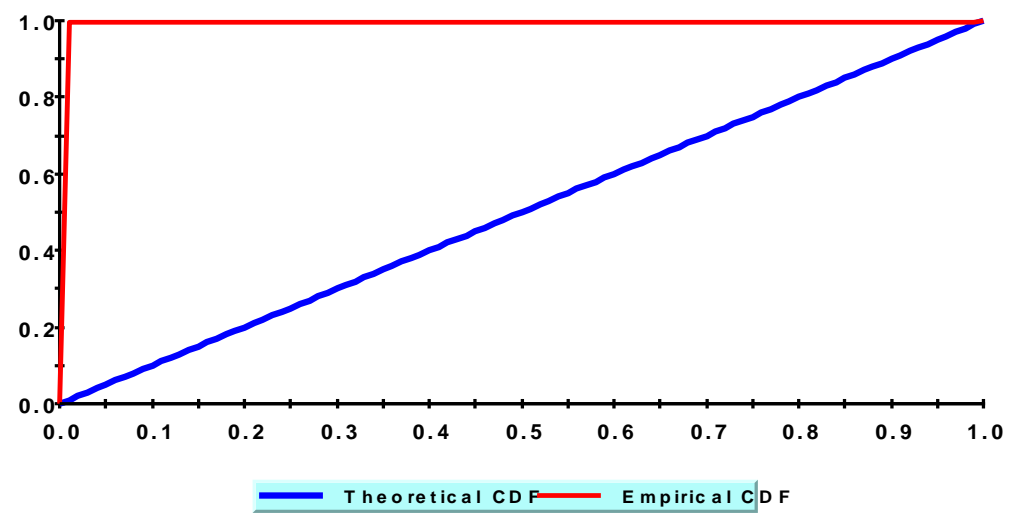

Figure 3. Kolmogorov-Smirnov Test of Normality 


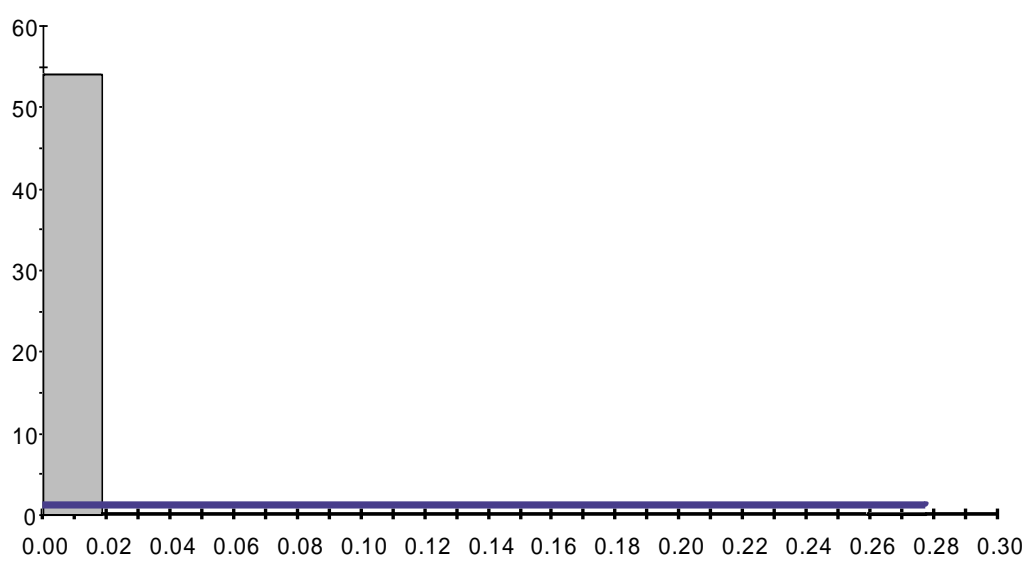

Histogram of the Probability Integra I T ransform

Figure 4. Histograms

Figure 5 presents the conditional correlations of the three countries in the sample (France, Germany and Greece) while in Figure 6 we present the forecasts of the volatilities over the period January 2008 to May 2014.

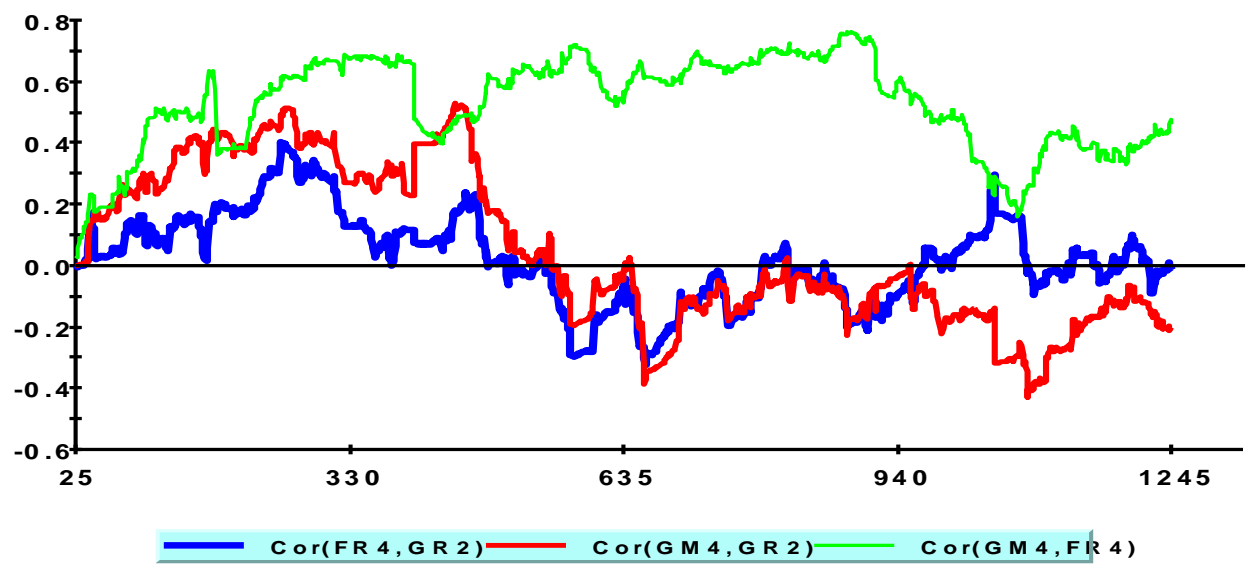

Figure 5. Conditional correlations of GR2, GM4, FR4 over the period January 07, 2008 to May 30, 2014

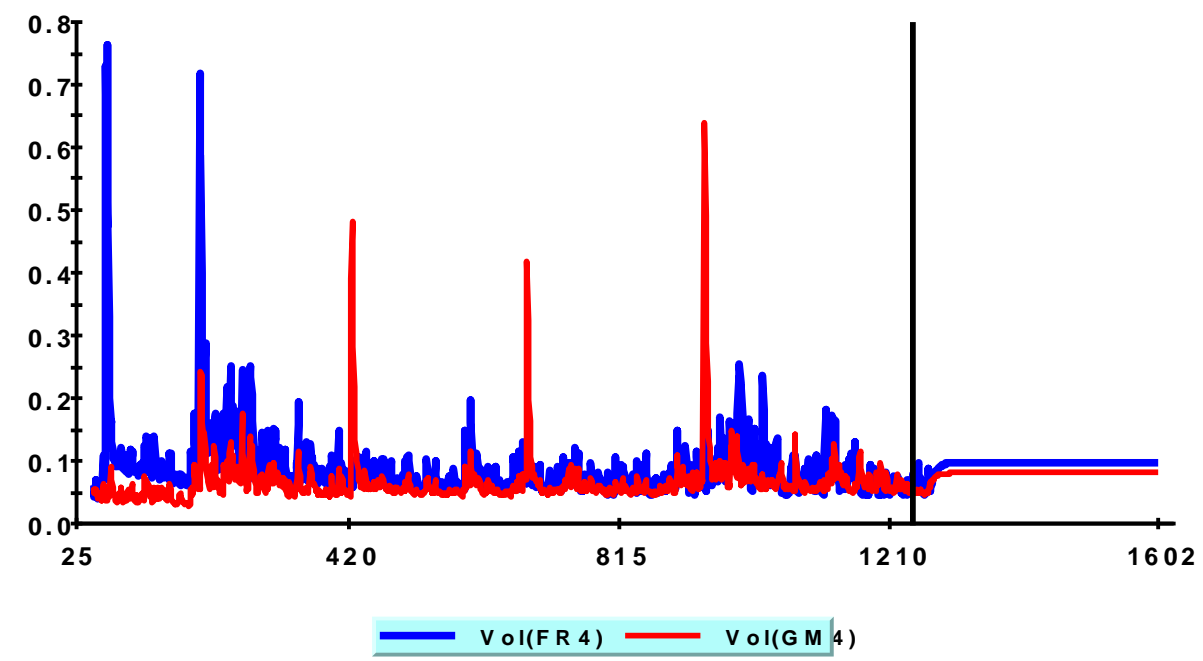




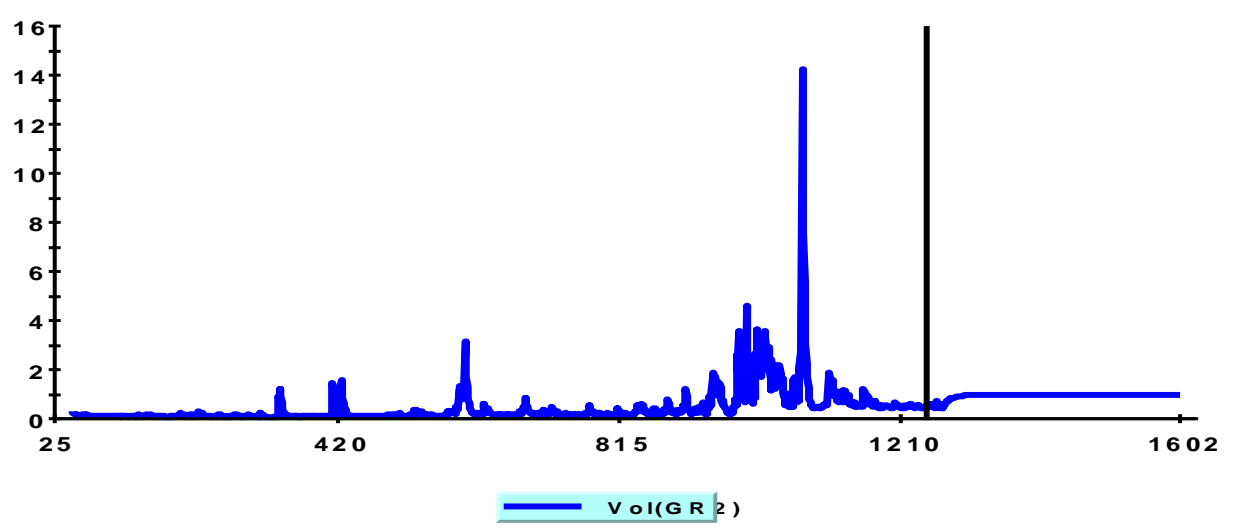

Figure 6. Forecast volatilities of GR2, GM4, FR4 over the period January 07, 2008 to May 30, 2014

\section{Conclusions}

We have introduced a three-variate M-GARCH model with an application to measure the risk of a bank's investment portfolio. By modeling the correlation structure, we have not only applied the Gaussian and $t$ distribution, but also the multivariate conditional volatilities and correlations which were rarely used because of the complexity involved in programming. To ascertain the exact dynamic relationship between observed financial variables is a difficult endeavor. This paper attempted to show that the two important financial variables, bond returns and equity prices, are correlated in a complicated manner. Any changes in prices of equity indexes have important implications for the value of government bonds. A three variate GARCH framework was used to reveal the dynamic relationship between GR2 (bonds of Greece), FR4 (bonds of France), GM4 (bonds of Germany) and three stock market indexes in Greece, France and Germany: ASE, CAC40, and DAX, respectively. It is shown that, although the unconditional correlation coefficient between bonds and stock market indexes are quite low and negative in the sample, the conditional correlations vary significantly over time. Additionally, conditional covariance and conditional volatilities aspects were plotted.

\section{References}

Bauwens, L., Laurent, S., \& Rombouts, J. (2006), Multivariate GARCH models: a survey, Journal of Applied Econometrics, 21(1), 79-109.

Bauwens, L., Omrane, W., Rengifo, E. (2010), Intradaily Dynamic Portfolio Selection, Computational Statistics and Data Analysis, 54, 2400-2418.

Bollerslev, T. (1990), Modelling the coherance in short run nominal exchange rates: a multivariate generalized ARCH Models, The Review of Economics and Statistics, 72(3), 498-505.

Bonato, M. (2012), Modeling fat tails in stock returns: a multivariate stable-GARCH approach, Computational Statistics, 27(3), 499-521.

Conrad, C., Karanasos, M., \& Zeng, N. (2011), Multivariate fractionally integrated APARCH modeling of stock market volatility: A multi-country study, Journal of Empirical Finance, 18, 147-159.

Engle, R. (2004), Risk and Volatility: Econometric Models and Financial Practice, The American Economic Review, 94(3), 405-420.

Fernández, B., \& Muriel, N. (2009), Regular variation and related results for the multivariate GARCH(p;q) model with constant conditional correlations, Journal of Multivariate Analysis, 100(7), 1538-1550.

Haas, M., Mittnik, S. and Paolella, M. S. (2009), "Asymmetric multivariate normal mixture GARCH”, Computational Statistics and Data Analysis, 53, 2129-2154.

Hafner, C.M. (2008), "Temporal aggregation of multivariate GARCH processes", Journal of Econometrics, 142(1), 467-483.

Hlouskova, J., Schmidheiny, K. \& Wagner, M., (2009), Multistep predictions for multivariate GARCH models: Closed form solution and the value for portfolio management, Journal of Empirical Finance, 16(2), 330-336.

Jerez, M., Casals, J., Sotoca, S. (2009), Likelihood stabilization for ill-conditioned vector GARCH models, Comput Stat, 24(1), 15-35.

Kawakatsu, H. (2006), Matrix exponential GARCH, Journal of Econometrics, 134(1), 95-128. 
Noureldin, D., Shephard, N., \& Sheppard, K. (2012), Multivariate high-frequency-based volatility (heavy) models, Journal of Applied Econometrics, 27(6), 907-934.

Santos, A. A. P., \& Moura, G. V., Torrent, H. D. S. (2012), Dynamic factor multivariate GARCH model, Computational Statistics and Data Analysis, available at www.eea-esem.com/files/papers/eea-esem/2012/2575/paper_factor_model_v6.pdf.

Serletis, A., \&Sajjadur, R. (2009), The Output Effects of Money Growth Uncertainty: Evidence from a Multivariate GARCH-in-Mean VAR, Open Economies Review, 20(5), 607-630.

Storti, G. (2008), Modeling asymmetric volatility dynamics by multivariate BL-GARCH models, Meth. \& Appl., 17, 51-274.

Thalassinos, I., Th. Kyriazidis, E., \& Thalassinos, J. E. (2006), The Greek Capital Market: Caught in between Poor Corporate Governance and Market Inefficiency', European Research Studies Journal, IX, 3-24.

Thalassinos, I. E., \& Pociovalisteanu, D. M. (2007), A Time Series Model for the Romanian Stock Market, European Research Studies Journal, X(3-4), 57-72.

Thalassinos, I. E., Hanias, P., Courtis, P., \& Thalassinos, E. J. (2009), Chaos Theory: Forecasting the Freight Rate of an Oil Tanker, International Journal of Computational Economics and Econometrics, 1(1), 76-88.

Thalassinos, I. E., Deceanu, L., Pintea, M., \& Zampeta, V. (2010), "New Dimensions of Country Risk in the Context of the Current Crisis: A Case Study for Romania and Greece”, European Research Studies Journal, XIII(3), $225-236$.

Thalassinos I. E., Maditinos D., \& Paschalidis A. (2012), Observing Evidence of Insider Trading in the Athens Stock Exchange (ASE), Journal of Economic Structures, 1(8), 52-67. http://www.journalofeconomicstructures.com/content/1/1/8

Thalassinos, I. E., Hanias, M. P., Curtis, P. G., \& Thalassinos, E. J. (2013), Forecasting Financial Indices: The Baltic Dry Indices, Marine Navigation and Safety of Sea Transportation: STCW, Maritime Education and Training (MET), Human Resources and Crew Manning, Maritime Policy, Logistics and Economic Matters, 283-306.

Tse, Y. K. (2000), A test for constant correlations in a multivariate GARCH model , Journal of Econometrics, 98(1), 107-127.

Ustun, O., Kasimbeyli, R. (2012), Combined forecasts in portfolio optimization: A generalized approach, Computers and Operations Research, 39(4), 805-819.

Zong-Run Wanga, X.-H., Jin, Yan-Bo \& Zhou, Yan-Ju (2010), Estimating risk of foreign exchange portfolio: Using VaR and CVaR based on GARCH-EVT-Copula model, Physica A: Statistical Mechanics and its Applications, 389, 4918-4928.

Appendix A: Regression Coefficients

Data for Regression Coefficients of Indexes (Greece, Germany and France)

Table 1.1 Germany

\begin{tabular}{cccc}
\hline Regressor & Coefficient & SE & T-test \\
\hline GM4(-1) & .99755 & .0021514 & $463.6776[.000]$ \\
DAX(-1) & $-.5944 \mathrm{E}-5$ & $.8826 \mathrm{E}-5$ & $-.67346[.501]$ \\
DAX(-2) & $-.8338 \mathrm{E}-5$ & $.9380 \mathrm{E}-5$ & $-.88893[.374]$ \\
DAX(-3) & $.1657 \mathrm{E}-5$ & $.9381 \mathrm{E}-5$ & $.17657[.860]$ \\
DAX(-4) & $.1365 \mathrm{E}-4$ & $.8834 \mathrm{E}-5$ & $1.5453[.123]$ \\
\hline
\end{tabular}

$\begin{array}{cccccc}\text { R-squared } & \text { R-bared-squared } & \text { DW-statistic } & \begin{array}{c}\text { Akaike info } \\ \text { criterion }\end{array} & \begin{array}{c}\text { Schwarz } \\ \text { Bayesian }\end{array} & \begin{array}{c}\text { F-statistic } \\ \text { regression }\end{array}\end{array}$


criterion

\begin{tabular}{lcccc}
\hline .99007 & 2.3869 & 1370.0 & 1357.2 & $\begin{array}{c}\mathrm{F}(4,1236) \\
30916.6[.000]\end{array}$ \\
\cline { 2 - 4 } & & & \\
\cline { 2 - 4 } & & & F-version \\
\hline Test A & LM-version & $\mathrm{F}(1,1235)=48.5659[.000]$ \\
Test B & $46.9553[.000]$ & $\mathrm{F}(1,1235)=.39126[.532]$ \\
Test C & $.39304[.531]$ & Not applicable \\
& $157132.9[.000]$ & $\mathrm{F}(1,1239)=3.2546[.071]$ \\
\hline
\end{tabular}

Table 1.2 France

\begin{tabular}{cccc}
\hline Regressor & Coefficient & SE & T-test \\
\hline FR4(-1) & .98331 & .0051473 & $191.0345[.000]$ \\
CAC40(-1) & $.2182 \mathrm{E}-3$ & $.4237 \mathrm{E}-4$ & $5.1497[.000]$ \\
CAC40(-2) & $-.2025 \mathrm{E}-3$ & $.5771 \mathrm{E}-4$ & $-3.5093[.000]$ \\
CAC40(-3) & $-.1353 \mathrm{E}-3$ & $.5767 \mathrm{E}-4$ & $-2.3465[.019]$ \\
CAC40(-4) & $.1369 \mathrm{E}-3$ & $.4231 \mathrm{E}-4$ & $3.2362[.001]$ \\
\hline
\end{tabular}

\begin{tabular}{ccccccc}
\hline R-squared & R-bared-squared & DW-statistic & $\begin{array}{c}\text { Akaike info } \\
\text { criterion }\end{array}$ & $\begin{array}{c}\text { Schwarz } \\
\text { Bayesian } \\
\text { criterion }\end{array}$ & $\begin{array}{c}\text { F-statistic } \\
\text { regression }\end{array}$ \\
\hline .96266 & .96254 & 1.3161 & 1131.0 & 1118.2 & F $(4,1236)$ & .097068 \\
& & & & $7966.5[.000]$ \\
\hline
\end{tabular}

\begin{tabular}{lcc}
\hline & LM-version & F-version \\
\hline Test A & $150.1065[.000]$ & $\mathrm{F}(1,1235)=169.9355[.000]$ \\
Test B & $4.5851[.032]$ & $\mathrm{F}(1,1235)=4.5798[.033]$ \\
Test C & $52177.5[.000]$ & Not applicable \\
Test D & $1.7366[.188]$ & $\mathrm{F}(1,1239) \quad=1.7362[.188]$ \\
\hline
\end{tabular}

Table 1.3 Greece

\begin{tabular}{cccc}
\hline Regressor & Coefficient & SE & T-test \\
\hline GR2(-1) & .99720 & .0021143 & $471.6518[.000]$ \\
ASE(-1) & $-.6920 \mathrm{E}-3$ & $.6070 \mathrm{E}-3$ & $-1.1400[.254]$ \\
ASE(-2) & $.4170 \mathrm{E}-3$ & $.8789 \mathrm{E}-3$ & $.47451[.635]$ \\
ASE(-3) & $.7865 \mathrm{E}-3$ & $.8779 \mathrm{E}-3$ & $.89593[.370]$ \\
ASE(-4) & $-.4991 \mathrm{E}-3$ & $.6047 \mathrm{E}-3$ & $-.82525[.409]$ \\
\hline
\end{tabular}




\begin{tabular}{|c|c|c|c|c|c|c|}
\hline R-squared & R-bared-squared & DW-statistic & $\begin{array}{c}\text { Akaike info } \\
\text { criterion }\end{array}$ & $\begin{array}{l}\text { Schwarz } \\
\text { Bayesian } \\
\text { criterion }\end{array}$ & F-statistic & $\begin{array}{l}\text { SE on the } \\
\text { regression }\end{array}$ \\
\hline \multirow[t]{2}{*}{.98769} & .98765 & 1.9535 & -1718.9 & -1731.7 & $\mathrm{~F}(4,1236)$ & .96480 \\
\hline & & & & & $24794.6[.000]$ & \\
\hline
\end{tabular}

\begin{tabular}{lcc}
\hline & LM-version & F-version \\
\hline Test A & $.67438[.412]$ & $\mathrm{F}(1,1235)=.67148[.413]$ \\
Test B & $22.8686[.000]$ & $\mathrm{F}(1,1235)=23.1853[.000]$ \\
Test C & $3234512[.000]$ & Not applicable \\
Test D & $45.9565[.000]$ & $\mathrm{F}(1,1239)=47.6469[.000]$ \\
\hline
\end{tabular}

\section{$($ cc) $\mathbf{E Y}$}

This work is licensed under a Creative Commons Attribution 3.0 License. 